\title{
The compatibility of earth-based repair mortars with rammed earth substrates
}

\author{
M. I. Gomes ${ }^{1}$, T. Diaz Gonçalves ${ }^{2}$ and P. Faria ${ }^{3}$ \\ 1. Lisbon Engineering Superior Institute (ISEL), Lisbon, Portugal, idaliagomes@dec.isel.ipl.pt \\ 2. National Laboratory for Civil Engineering (LNEC), Portugal, teresag@lnec.pt \\ 3. Nova University of Lisbon, Lisbon (UNL-FCT), Portugal, paulina.faria@fct.unl.pt
}

\begin{abstract}
Earth constructions are susceptible to degradation due to natural or human causes. The degradation of the exterior surface of earth walls is very common, either due to lack of maintenance or to the use of incompatible materials, and often requires the application of a repair mortar. This work experimentally analyses the performance of earth-based repair mortars applied on rammed earth surfaces. The mortars are based on earth collected from rammed earth buildings in south Portugal or on a commercial earth. Eight repair mortars were formulated, with the unstabilized soils or including a small binder content. Four types of binder were tested: hydrated air-lime, natural hydraulic lime, Portland cement and natural cement. The repair mortars were applied on two types of standard defects purposely made on rammed earth blocks, representing the most current common defects found on exterior rammed earth surfaces: a standard superficial defect and a standard deep defect. The performance of the mortars, their compatibility with the substrates and the visual effectiveness of the intervention were evaluated. It was concluded that the mortars behaved differently when applied on different rammed earth supports. However, the best performances occurred always for the mortars made from unstabilized soil identical to that of the rammed earth substrate. Indeed, the use of stabilizers systematically worsened the behavior of the repair mortars, regardless of the type of binder used for that purpose.
\end{abstract}

Keywords: rammed earth substrates, earth repair mortars, compatibility between materials

\section{Introduction}

In a society where questions related to sustainable development and ecology start to matter, the use of locally sourced, non-processed building materials, such as natural earth, is a possible path for a greener economy. Other advantages of earth as a building material are its abundance, low cost and ease of recycling.

In Portugal, the number of new rammed earth constructions is increasing, as is the number of old rammed earth building being restored for modern uses. The degradation of the exterior surface of earthen walls is very common, either due to a lack of maintenance which eventually conducts to direct exposure to the environment, or to the application of incompatible renders or other materials. Restoring the functionality and aesthetics of these walls often requires the application of a repair mortar.

Aiming at the development of appropriate repair mortars for rammed earth constructions, eight repair mortars were produced with four types of soil and tested on three types of rammed earth substrates. This study is important, insofar as the authors are not aware of other studies in which earth mortars are applied to a substrate, allowing a direct assessment of the compatibility between them. The substrates consisted of rammed earth blocks manufactured in the lab for that purpose with soil collected from old rammed earth buildings. Standard defects - superficial irregularities and deep voids - were created on the surface of these blocks, representing those commonly found in the exterior surfaces of rammed earth walls (Gomes and Faria 2011). The eight repair mortars were based on either the same earth as the substrate or a 
commercial earth. The commercial earth was used in its natural state or after stabilization with a small amount of hydrated air-lime, natural hydraulic lime, Portland cement or natural cement.

The earth-based mortars were applied onto two types of standard defects - a standard superficial defect and a standard deep defect - in order to evaluate their behaviour as repair mortars. The repair of deep defects was made in two different ways - the voids were filled only with mortar or with a mortar and coarse gravel(added to reduce the mortar's thickness).

The present article describes and discusses this work which is part of a more general project that included artificial ageing tests to assess the adequacy of earth-based mortars as repair mortars for rammed earth materials.

\section{Materials}

Four types of earth were used in this study. Three of them (earths Av, PD and VC) were collected from non deteriorated parts of walls of unstabilized rammed earth buildings located in the Alentejo region of Southern Portugal. These three earths were chosen because they represented different grain size distributions and types of clay. Av is more sandy than PD and VC, which are more clayey. The fourth (earth RE) is a commercial earth, composed mainly of clay. The four materials are fully characterized elsewhere (Gomes et al. 2012a, Gomes et al. 2012b).

The uniformity of the particle size distribution (PSD) was ensured as it is a important factor when studying such material. A uniform PSD allows for a more efficient compaction because the grains can align in a way that minimizes the empty spaces between them (Keable 1996; Walker et al. 2005). It is commonly accepted that the more compact the material, in principle, the lower the porosity and the higher the mechanical resistance; hence a greater durability (Keable 1996; Walker and Australia 2001; Walker et al. 2005). Morton (2004) also notes that buildings with earthen well-graded materials can be remarkably durable, while poorly graded mixes never perform well.

\subsection{Rammed earth blocks}

The rammed earth blocks were produced with the site-collected earths Av, PD, and VC. The preparation of the material is detailed in Gomes et al. (2012c). It was first disaggregated with a rubber hammer so (not to break the aggregates) and then dry sieved, rejecting the material that passed through the $12.5 \mathrm{~mm}$ sieve ( $1 / 2 "$ ASTM).

\subsection{Mortars}

The compositions of the eight repair mortars are presented in Table 1. As seen, the mortars with clayish earths include sand. The sand is composed mainly of quartz and has a grain dimension in the range 0.6 to $2.0 \mathrm{~mm}$. Its addition had the main objective of reducing the shrinkage of the mortar which otherwise would be very high due to the clay content of the earths. The MRE mortars include also $15 \%$ of powder hydrated air-lime (AL), natural hydraulic lime (NHL), Portland cement (PC) or natural cement (NC).

The earth was prepared as follows: (i) the three earths (Av, PD, VC) collected from the buildings were wet sieved through a $2 \mathrm{~mm}$ sieve $\left(\mathrm{N}^{\circ} 10\right.$ ASTM); the material that passed through the sieve, after decanting, was dried in a ventilated oven at $40{ }^{\circ} \mathrm{C}$; it was ground and homogenized; (ii) the comercial earth (RE) was ground to disaggregate the material before the sample was homogenized.

Figure 1 shows the particle-size distribution of the unstabilized materials for the mortars, MAv, MPD, MVC and MRE.

To fill some of the standard deep defects coarse gravel with dimensions between 20 and $40 \mathrm{~mm}$ was also used to reduce the thickness of the mortar. 
Table 1: Composition of the eight mortars

\begin{tabular}{|c|c|c|c|c|c|c|c|}
\hline \multirow{2}{*}{$\begin{array}{l}\text { Group of earth based } \\
\text { mortars }\end{array}$} & \multirow{2}{*}{$\begin{array}{l}\text { Designation of } \\
\text { the mortar }\end{array}$} & \multirow{2}{*}{$\begin{array}{c}\text { Weight } \\
\text { proportions } \\
\text { (clay:sand) }\end{array}$} & \multirow{2}{*}{$\begin{array}{l}\text { Volumetric } \\
\text { proportion } \\
\text { (clay:sand) }\end{array}$} & \multicolumn{4}{|c|}{ Stabilizant $(\%)^{*}$} \\
\hline & & & & $\mathrm{AL}^{(1)}$ & $\mathrm{NHL}^{(2)}$ & $P C^{(3)}$ & $\mathrm{NC}$ \\
\hline Local earth Av & MAv & $1: 0$ & $1: 0$ & - & - & - & - \\
\hline Local earth PD & MPD & $1: 1,9$ & \multirow{2}{*}{$1: 1,5$} & - & - & - & - \\
\hline Local earth VC & MVC & $1: 2,4$ & & - & - & - & - \\
\hline Reference-earth & MRE & \multirow{5}{*}{$1: 3,8$} & \multirow{5}{*}{$1: 3$} & - & - & - & - \\
\hline $\begin{array}{c}\text { Reference-earth with } \\
\text { hydrated air-lime }\end{array}$ & MRE_AL15 & & & 15 & - & - & - \\
\hline $\begin{array}{l}\text { Reference-earth with } \\
\text { natural hydraulic lime }\end{array}$ & MRE_NHL15 & & & - & 15 & - & - \\
\hline $\begin{array}{l}\text { Reference-earth with } \\
\text { Portland cement }\end{array}$ & MRE_PC15 & & & - & - & 15 & - \\
\hline $\begin{array}{l}\text { Reference-earth with } \\
\text { natural cement }\end{array}$ & MRE_NC15 & & & - & - & - & 15 \\
\hline
\end{tabular}

$*$ Percentages by weight in relation to the reference earth.

${ }^{(1)}$ EN 459-1 CL 90-S; ${ }^{(2)}$ EN 459-1 NHL5 and ${ }^{(3)}$ CEM II/BL $32.5 \mathrm{~N}$.

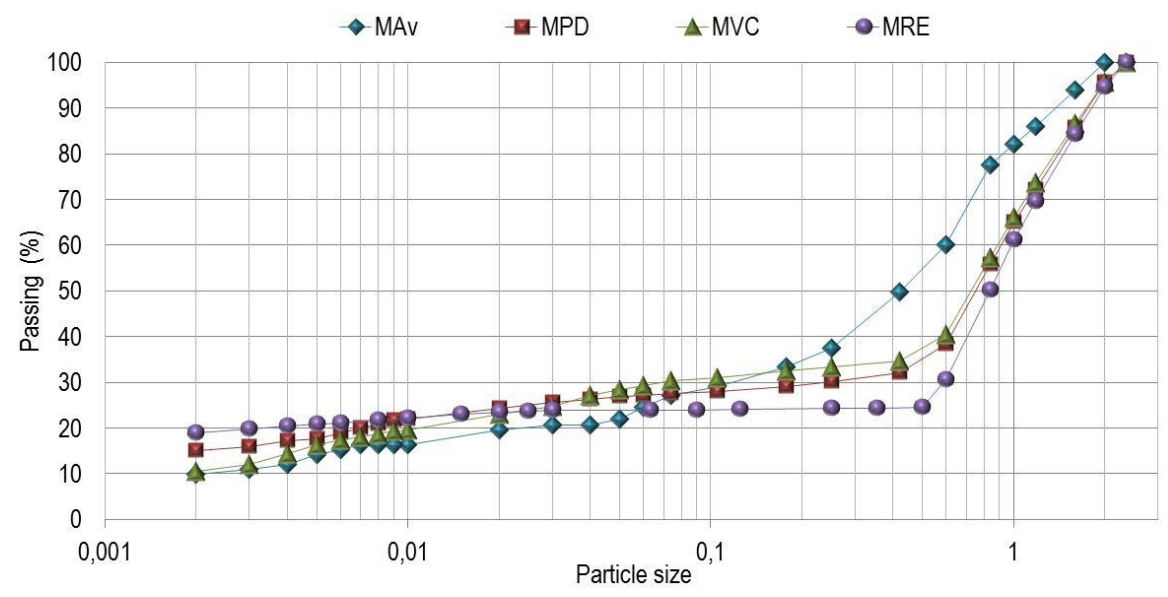

Figure 1: Particle size distribution of the mortar materials, MAv, MPD, MVC and MRE

\section{Experimental methodology}

\subsection{Rammed earth blocks}

Ten rammed earth blocks, with dimensions $30 \mathrm{~cm} \times 20 \mathrm{~cm} \times 28 \mathrm{~cm}$, were manufactured with each type of collected earth (BAv, BPD and BVC). The two types of current defects : superficial loss of material $(2 \mathrm{~cm}$ depth) and deep voids (semi sphere with $10 \mathrm{~cm}$ diameter), were recreated on the blocks: The blocks were kept in a controlled environment at $20^{\circ} \mathrm{C}$ and $50 \% \mathrm{RH}$ for 20 months. Details of their manufacture can be found in Gomes et al. (2012c).

\subsection{Preparation and caracterization of the earth-based mortars}

For the mixing of the mortars, EN 196-1 was followed as closely as possible. A mechanical mixer was used composed of a 3 litre stainless steel vat and a paddle mixer driven by an electric motor.

The methodology used for mortars MAv, MPD and MVC was as follows: (i) manual homogenization of the material; (ii) introduction of water into the mixer, followed by introduction of the dry material; (iii) 
mixing at low speed for 90 seconds; (iv) a 90 second halt (in the first 15 seconds the mortar adhering to the walls of the vat was removed with a rubber spatula and added to the remaining mortar); (v) mixing at low speed for another 60 seconds.

For the MRE mortar it was necessary to increase the mixing time because a good homogenization would not be achieved otherwise due to the large clay content. Thus, after (ii) the mortar was manually mixed for an extra period of 2 minutes and (iii) was prolonged to 150 seconds.

The consistence by flow table, EN 1015-3 (Table 2), was used to determine the amount of water in the mortars. The quantity of water was added so that the flow values were adjusted to the target interval of 160-176 mm which corresponds to earth-based mortars with excellent workability (Gomes et al 2012c).

It was also important to limit the shrinkage of the mortars (Gomes et al 2012c). The linear shrinkage of raw earth materials is commonly evaluated by Alcock's test (also called the shrink-box test). Linear shrinkage should not be more than 3\% in accordance with the New Zealand Standard (SNZ 4298, 1998). Interetingly, linear shrinkage does not appear to be representative of total shrinkage therefore volumetric shrinkage was also determined (Gomes et al. 2012a, Gomes et al. 2012b).

Table 2: Water/dry material ratio, flow table consistency, linear and volumetric shrinkage of the eight earth-based mortars

\begin{tabular}{ccccc}
\hline \multirow{2}{*}{$\begin{array}{c}\text { Mortar } \\
\text { designation }\end{array}$} & $\begin{array}{c}\text { Water/dry } \\
\text { material ratio }\end{array}$ & \multirow{2}{*}{$\begin{array}{c}\text { Flow } \\
(\mathrm{mm})\end{array}$} & \multicolumn{2}{c}{ Shrinkage (\%) } \\
\cline { 4 - 5 } MAv & 0,13 & 174 & $\approx 0$ & Linear \\
\hline MPD & 0,20 & 177 & $1,00 \pm 0,18$ & $1,25 \pm 0,23$ \\
\hline MVC & 0,21 & 177 & $1,35 \pm 0,36$ & $1,46 \pm 0,15$ \\
\hline MRE & 0,31 & 170 & $0,90 \pm 0,12$ & $0,95 \pm 0,08$ \\
\hline MRE_AL15 & 0,30 & 170 & $1,36 \pm 0,31$ & $6,21 \pm 0,27$ \\
\hline MRE_NHL15 & 0,29 & 172 & $0,57 \pm 0,38$ & $5,49 \pm 0,50$ \\
\hline MRE_PC15 & 0,29 & 180 & $0,37 \pm 0,06$ & $3,19 \pm 1,00$ \\
\hline MRE_NC15 & 0,29 & 159 & $1,72 \pm 0,06$ & $6,11 \pm 0,54$ \\
\hline
\end{tabular}

\subsection{Application technique of the repair mortars}

The three mortars MAv, MPD e MVC that correspond to local earths were applied only in the blocks made from the same earth. Consequently, the commercial earth mortars (MRE) are intended for general use and, therefore, were applied on the three types of rammed earth blocks. For each mortar three applications were always carried out, either to the standard superficial defect or for each type of deep defect filling.

Before applying the mortars the rammed earth surfaces were prepared as follows:

(i) the repair area was brushed to remove loose particles and dust;

(ii) the surface was wet by spraying for $30 \mathrm{~min}, 20 \mathrm{~min}, 10 \mathrm{~min}$ and $30 \mathrm{sec}$ before applying the mortar to avoid a sudden drying out of the mortar, thereby preventing a large initial retraction.

The application technique of the repair mortars in the superficial defects was as follows (Figure 2):

(i) the mortar was thrown vigorously against the support with a trowel, always from the bottom to the top;

(ii) the mortar was tightened and repointing was performed particularly in the corners, with a trowel;

(iii) the surface of the mortar was made regular with a wooden or metal ruler;

(iv) the surface of the mortar was smoothed with a sponge.

In the case of the deep defects the mortar was applied using the following procedure (Figure 3):

(i) the mortar was launched vigorously against the support with a trowel followed by tightening; the thickness of this first mortar layer was of 0.5 to $1 \mathrm{~cm}$;

(ii) in the case of using coarse gravel to partially fill the holes of the defects these were applied after this first layer of mortar;

(iii) the interval of 15-20 min between the application of mortar layers was respected so that the previous layer had time to achieve enough resistance; 
(iv) the application of the last layer of mortar was careful, especially in the zone of connection with the support; repointing was carried out where necessary;

(v) the surface was made regular with a wooden or metal ruler;

(vi) finally the surface was smoothed with a sponge.

Immediately after application of the mortar the initial shrinkage begins; this is inhibited by adhesion to the support. This shrinkage leads to the development of shear stresses in the plane of contact between the mortar and the support. This can cause detachment and/or tensile stress in the mortar which can cause cracking. Because of this it was necessary to repoint some cracks. Cracks appeared in the mortars approximately 2 to 3 hours after application, on both types of standard defects and on both types of deep hole defect repairs (with and without coarse gravel). The repointing was undertaken 4 hours after application.
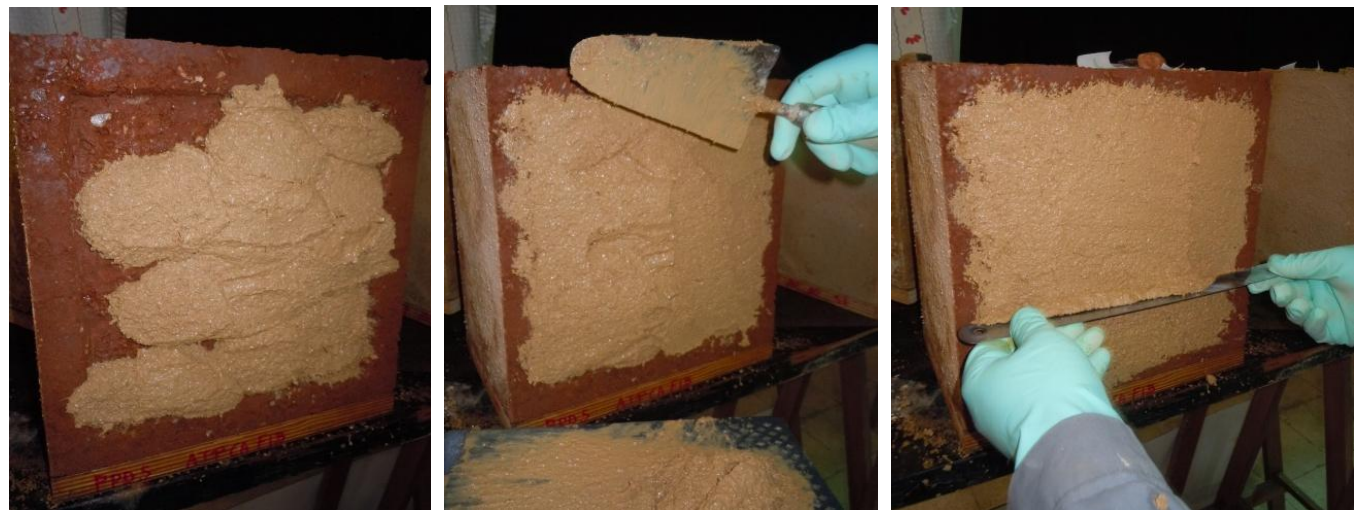

Figure 2: Application of the mortar MRE_AL15 on a standard superficial defect of the PD rammed earth
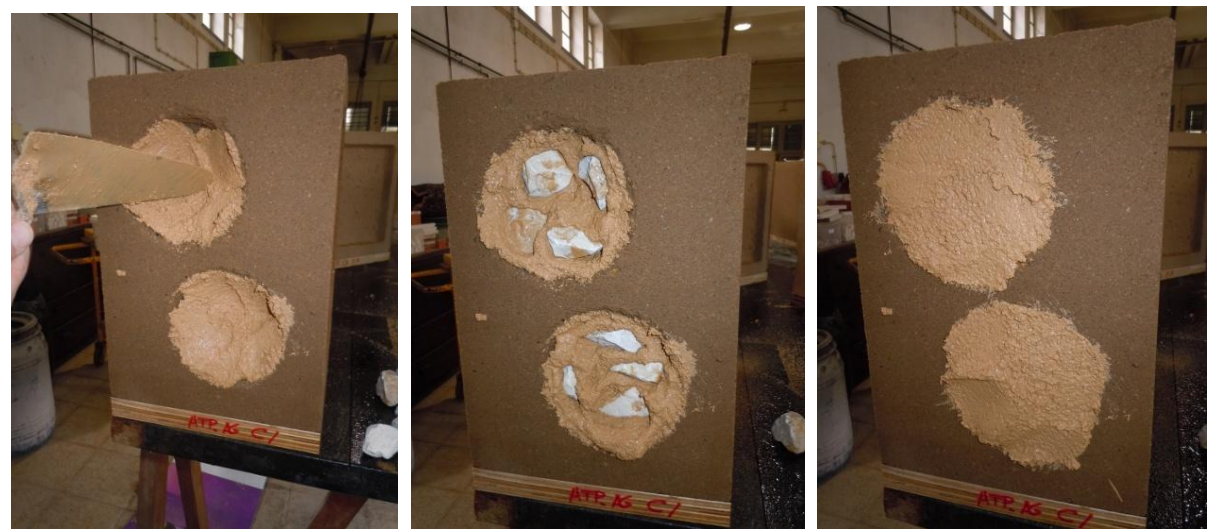

Figure 3: Application of the mortar MRE on a standard deep voids defect of the Av rammed earth

\section{Results and discussion}

The performance of the repair mortars, in terms of workability, was evaluated in a fresh state. All the mortars were found to have a good workability. When hardened, the mortars were evaluated 10, 30 and 90 days after their application on the blocks. However, no changes were detected between the 10 and 90 days, which means that most of the shrinkage occurred before then.

Tables 3 and 4 summarize the observed anomalies which were: micro cracks; medium cracks, large cracks, and loss of adhesion between the mortar and the support rammed earth blocks BAv, BPD and BVC. The classification of cracking in the mortar was based on the respective opening, adopting the French standard NF P 84-401 (Veiga 1998), which details the following specifications for cracks within stabilized renders and plasters: micro cracks - width less than $0.2 \mathrm{~mm}$; medium cracks - width between 0.2 and $2 \mathrm{~mm}$ and large cracks - width greater than $2 \mathrm{~mm}$. 
Table 3: Main decay patterns of the repair mortars applied on the standard superficial defect

\begin{tabular}{|c|c|c|c|}
\hline & BAv & BPD & $\mathrm{BVC}$ \\
\hline MAv & micro cracks ${ }^{(1)}$ & - & - \\
\hline MPD & - & micro + medium cracks ${ }^{(1)}$ & - \\
\hline MVC & - & - & micro ${ }^{(1)}$ cracks \\
\hline MRE & medium cracks & medium cracks $^{(2)}$ & micro ${ }^{(1)}+$ medium cracks \\
\hline MRE_AL15 & $\begin{array}{c}\text { micro }+ \text { medium cracks } \\
\text { loss of adhesion }\end{array}$ & medium cracks & micro + medium $^{(2)}$ cracks \\
\hline MRE_NHL15 & micro + medium cracks & micro + medium cracks ${ }^{(2)}$ & micro + medium cracks ${ }^{(2)}$ \\
\hline MRE_PC15 & $\begin{array}{l}\text { medium cracks } \\
\text { loss of adhesion }\end{array}$ & medium cracks ${ }^{(2)}$ & medium cracks \\
\hline MRE_NC15 & $\begin{array}{l}\text { micro + large cracks }{ }^{(2)} \\
\text { loss of adhesion }\end{array}$ & micro + medium cracks & micro + medium cracks ${ }^{(2)}$ \\
\hline
\end{tabular}

(1) only contour cracks

(2) cracks only in the mortar

Table 4: Main decay patterns of the repair mortars applied on the standard deep defect

\begin{tabular}{|c|c|c|c|}
\hline & BAv & BPD & $\mathrm{BVC}$ \\
\hline MAv & 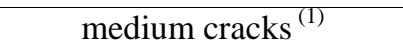 & - & - \\
\hline MPD & - & micro + medium cracks $^{(1)}$ & - \\
\hline MVC & - & - & micro + medium cracks ${ }^{(1)}$ \\
\hline MRE & micro $^{(2)}+$ medium cracks $^{(1)}$ & not visible & micro $^{(1)}+$ medium cracks ${ }^{(2)}$ \\
\hline MRE_AL15 & micro + medium cracks $^{(1)}$ & micro $^{(1)}+$ medium cracks & micro $^{(1)}+$ medium cracks \\
\hline MRE_NHL15 & medium cracks ${ }^{(1)}$ & micro $^{(2)}+$ medium cracks ${ }^{(1)}$ & micro $^{(2)}+$ medium cracks \\
\hline MRE_PC15 & ${\text { medium } \text { cracks }^{(1)}}^{(1)}$ & medium cracks & medium cracks \\
\hline MRE_NC15 & $\begin{array}{l}\text { medium cracks }{ }^{(1)} \\
\text { loss of adhesion }\end{array}$ & micro $^{(2)}+$ medium cracks ${ }^{(1)}$ & $\begin{array}{c}\text { micro }^{(2)}+\text { medium }^{(1)}+ \\
\text { large }^{(2)} \text { cracks }^{-}\end{array}$ \\
\hline
\end{tabular}

(1) only contour cracks

(2) cracks only in the mortar
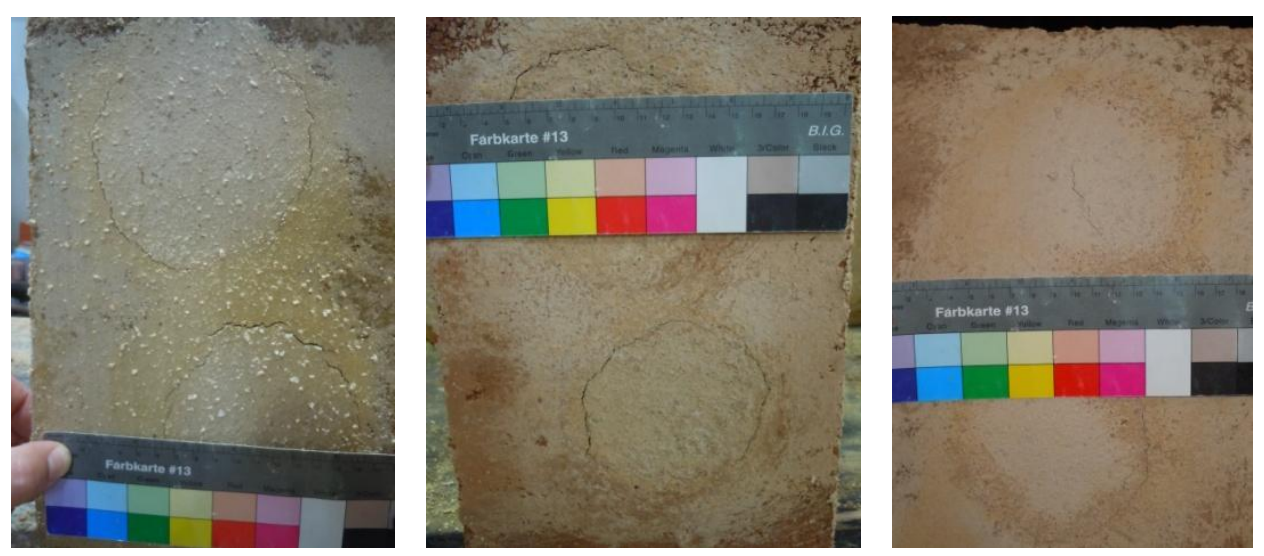

Figure 4: Medium cracks on the mortar MRE_AL15 applied on the standard deep void defects in the blocks: left, in BAv; center, in BPD; and right, in BVC

Analyzing the anomalies observed for the eight families of mortars (Tables 3 and 4 ), it is seen that:

(i) the unstabilized mortars MAv, MPD and MVC applied on blocks of the same type of earth showed the best performance, presenting just contour cracks; 
(ii) the performance of the stabilized MRE-based mortars (Figure 4) was always worse than that of the unstabilized MRE mortars: cracking was more intense and was sometimes accompanied by detachment of the repair mortar;

(iii) loss of adhesion between the mortar and the support was verified only for the Av substrate which has a low clay content;

(iv) the incorporation of gravel did not prevent or reduce the occurrence of anomalies in the mortars applied on the deep standart defect.

Unstabilised mortars had only few cracks and did not detach from the substrate. This is due to their lower shrinkage rate (Table 2) and to the fact that they have mechanical characteristics closest to those of the substrate. The similarity between the mortar and the sustrate is particularly relevant for the MAv, MPD and MVC mortars which were applied on blocks of the same type of earth and, in fact, were the ones with better behaviour. This assertion is corroborated by Morton(2004), who assertains that the compatibility of materials is a favourable criterion in their durability. He also states that constructions are more vulnerable to progressive decay at the interface between different materials, e.g. when other denser materials are applied to the surface.

The stabilized mortars behaved worse, particularly in the case of the BAv substrate where detachement of the whole repair occurred in several cases (Figure 5). This was probably due to the lower adesion provided by this relatively high sand content susbtrate.

On the deep standard defects, the incorporation of coarse gravel did not improve the performance of the repair mortars. However, it facilitated their application because it decreased the amount of mortar used. It also made the application quicker because the repair was achieved with fewer mortar coats.

These results validate that in practice, it will be more appropriate to repair unstabilized rammed earth walls by means of unstabilized mortars, preferably based on earth similar to that of the substrate. The repair philosophy must be that of: "minimum intervention to ensure long-term stability and optimum performance of the structure without causing physical disruption” (Maniatidis and Walker 2003, p.72).
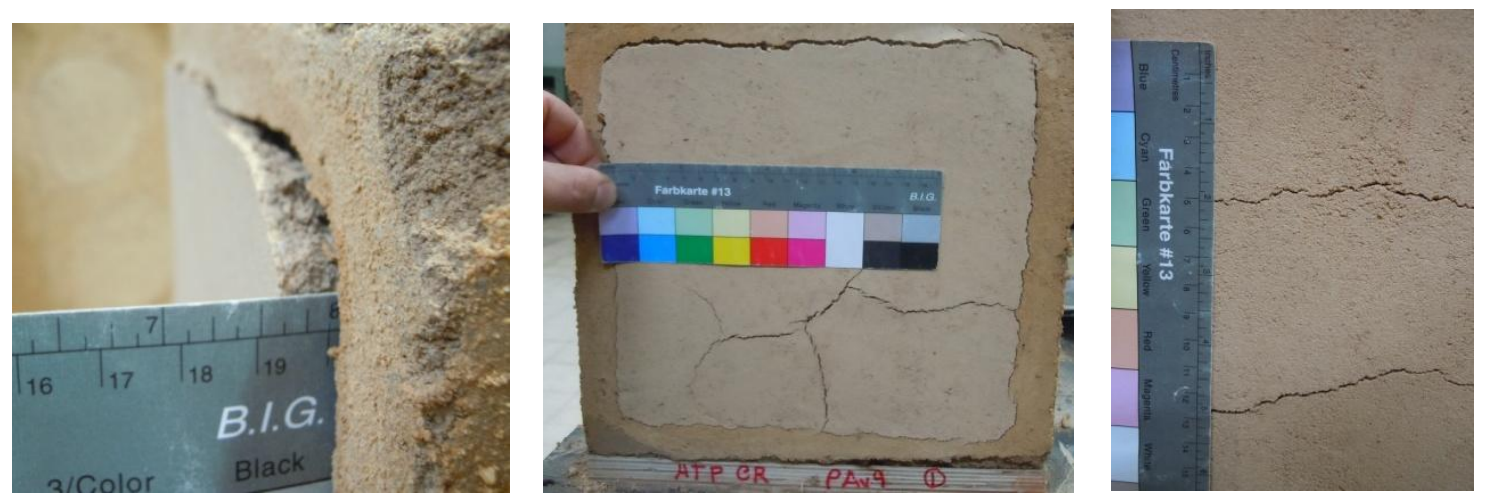

Figure 5: Mortar MRE_NC15 applied in block BAv on standard surperficial defect: left, detachment of the mortar; center, cracks; and right, detail of large cracks

\section{Conclusions}

Mortars behaved differently when applied on different rammed earth supports. The best performance occurred in the mortars that were composed of unstabilized soil that was identical to the rammed earth substrate. An application of protective render or plaster can be used to reinstate the wall thickness and repair and micro and medium cracks when they appear.

The incorporation of low amounts of the non earth binders, used as stabilisers, systematically worsened the behavior of the repair mortars, regardless of the type of binder. This indicates that in practice, it will be more appropriate to repair unstabilized rammed earth walls by means of unstabilized mortars, preferably based on earth similar to that of the wall itself. This also has additional conservation benefits as it enables the repair of the structure on a like for like materials basis. 


\section{Acknowledgements}

M.I. Gomes is supported by a doctoral grant from the Fundação para a Ciência e a Tecnologia (FCT). This work was carried out at the National Laboratory for Civil Engineering (LNEC), in Lisbon. The authors are grateful to the people who collaborated in the experimental work, in particular LNEC technicians José Costa, João Junior, Luis Nunes, and Bento Sabala. We wish to thank the following companies for their aid : Sorgila company, Lusical and Secil, Georg Hilbert and Aubiose.

\section{References}

CEN, EN 196-1, (2005). Methods of testing the cement - Part 1: Determination of mechanical strength. Brussels: CEN.

Gomes, M.I. and Faria, P., (2011). Repair mortars for rammed earth constructions. Proceedings of the $12^{\text {th }}$ International Conference on Durability of Building Materials and Components, Freitas V.P., Corvacho H. and Lacasse (eds), Faculdade de Engenharia da Universidade do Porto, Portugal, 2, 689-696.

Gomes, M.I., Gonçalves, T.D. and Faria, P., (2012a). Análise experimental de argamassas de terra com cais e fibras naturais. Proceedings of the $4^{\text {th }}$ Congresso Português de argamassas e ETICS - APFAC. Coimbra, Cd Proceddings.

Gomes, M.I., Gonçalves, T.D. and Faria, P., (2012b). Earth-based repair mortars : experimental analysis with different binders and natural fibers. Proceedings of the $1^{\text {st }}$ International Conference on Rammed Earth Conservatio, Mileto C., Vegas F., and Cristini V. (eds), Valencia, Spain, 21-23.

Gomes, M.I., Gonçalves, T.D. and Faria, P., (2012c). Evaluación de la influencia del contenido de agua en la trabajabilidad del mortero de tierra. APUNTES, 25(2), 8-27.

Gomes, M.I., Gonçalves, T.D. and Faria, P., (2012d). Unstabilised rammed earth: characterization of the material collected from old constructions in south Portugal and comparison to normative requirements. International Journal of Architectural Heritage, (online since 22 april 2012), doi 10.1080/15583058.2012.683133.

Keable, J., (1996). Rammed Earth Structure: a code of pratice, London: Intermediate Technology Publications Ltd.

Maniatidis, Vasilios, and Peter Walker., (2003). A Review of Rammed Earth Construction. Review Literature And Arts Of The Americas DTi Partne (May).

Morton, T., (2004). Earth Structures, Renders and Plasters: Experiments in Historical Techniques and Weathering. In 4th International Conference on Building with Earth, LEHM. Dachverband Lehm e.V (eds). Weimar, Germany, 29-30 October 2004. ISBN: 3000148647. 272-275

SNZ, 4298, (1998). Materials and workmanship for earth buildings. Standards New Zealand. New Zealand.

Veiga, R., (1998). Behavior of mortar coating walls. Contribution to the study of its resistance to cracking (in Portuguese). PhD thesis, Faculty of Engineering of University of Porto.

Walker, P., Keable, R., Martin, J., and Maniatidis, V. (2005). Rammed earth: design and construction guidelines, Watford: BRE Bookshop. ISBN 186081734 3, 146.

Walker, P. and Australia, S., (2001). HB 195: The australian earth building handbook, Sydney, Australia: Standards Australia International Ltd. ISBN. 0733740006, 151. 